\title{
New Developments in Kisspeptin, Neurokinin B and Dynorphin A Regulation of Gonadotropin- Releasing Hormone Pulsatile Secretion
}

\author{
Robert P. Millar \\ Mammal Research Institute, University of Pretoria, Pretoria, South Africa
}

The KNDy neuropeptides kisspeptin, neurokinin B (NKB) and dynorphin A (Dyn), play a pivotal role in regulating pulsatile gonadotropin-releasing hormone $(\mathrm{GnRH})$ secretion. There are, however, relatively few studies attempting to integrate the interactions between KNDy-signalling systems. This special issue assembles three articles on this topic from studies on laboratory rats, sheep and humans. These reports go some way to clarifying kisspeptin, $\mathrm{NKB}$ and Dyn interactions in regulating pulsatile GnRH secretion and highlight species differences in the interplay and roles of these upstream regulators.

In their article, Grachev et al. [1] point out that although the stimulatory effect of kisspeptin and the inhibitory effect of Dyn on the GnRH pulse generator are widely accepted, the effects of NKB in rodents are variable and sometimes controversial. Literature describing increased secretion of luteinizing hormone $(\mathrm{LH})$ in response to $\mathrm{NKB}$ receptor agonism predominates and is in line with human physiology as well as with the pathophysiology of pubertal failure associated with disruption of NKB signalling. However, under hypoestrogenic conditions NKB exhibits a robust suppression of $\mathrm{LH}$, which may shed light on the mechanisms of reproductive inhibition under pathological conditions such as anorexia nervosa. The article provides a revised working model in- corporating the mechanisms by which KNDy neuropeptides modulate the reproductive axis (see [1] and the cover of this issue).

The second article, by Goodman et al. [2], reviews the roles of kisspeptin, NKB and Dyn in GnRH pulse generation as gathered from a comprehensive series of excellent studies in sheep from their laboratory as well as from equally detailed and incisive experiments in goats [for a review, see 3], which led to the promulgation of a model proposing a role for the KNDy neuron NKB in stimulating kisspeptin to initiate a $\mathrm{GnRH}$ pulse. NKB also stimulated Dyn release from KNDy neurons to inhibit their activity and terminate the GnRH pulse. Further studies using a range of agonists and antagonists of kisspeptin, NKB and Dyn led to the development of a modified model which invokes an action for kisspeptin in activating unidentified KNDy neurons which reinforce the stimulatory actions of NKB on KNDy neurons [see 2, fig. 11].

The third article reviews the sexually dimorphic distribution of kisspeptin, NKB and Dyn in the male and female human brain and changes that occur with aging. Hrabovszky [4] points out that in various mammalian species, the majority of kisspeptin-synthesizing neurons are concentrated in two distinct cell populations in the

\section{KARGER}

E-Mail karger@karger.com

www.karger.com/nen
(C) 2014 S. Karger AG, Basel

0028-3835/14/0991-0005\$39.50/0
Robert P. Millar

Mammal Research Institute, University of Pretoria

Pretoria 0028 (South Africa)

E-Mail robertpetermillar@gmail.com 
preoptic region and in the arcuate nucleus (ARC). Studies of female rodents have provided evidence that preoptic kisspeptin neurons play a crucial sex-specific role in positive oestrogen feedback, but kisspeptin neurons of the ARC are implicated in negative sex steroid feedback and regulation of pulsatile GnRH secretion. Except for relatively few morphological studies available on monkeys and humans, our neuroanatomical knowledge of the hypothalamic kisspeptin systems is predominantly based on observations of laboratory species which are phylogenetically distant from the human. To address this issue, the author [4] reviews the currently available literature on the topographic distribution, network connectivity, neurochemistry, sexual dimorphism and aging-dependent morphological plasticity of the human hypothalamic KNDy neuronal system.

Although there remain a number of unresolved questions concerning the role of NKB, Dyn and kisspeptin in $\mathrm{GnRH}$ pulse generation, there is a consensus that NKB operates upstream of kisspeptin to modulate downstream GnRH pulsatility. Strong support for this notion is provided by studies on infertile patients with NKB- or NKB receptor-inactivating mutations, continuous kisspeptin infusion restored pulsatile LH $(\mathrm{GnRH})$ secretion [5].
However, this observation brings into question (at least in humans) whether NKB is at all involved in pulse generation.

The last article in this issue, by Matsui and Asami [6], addresses matters concerning the role of the kisspeptin system in regulating $\mathrm{GnRH}$ by utilizing kisspeptin agonist and antagonist analogues in animals and humans. The therapeutic potential of kisspeptin has been extensively explored, but its susceptibility to proteolytic degradation limits its utility. To overcome this, KiSS1R agonists or antagonists as peptide analogues or small molecules were developed. By reducing the length of the peptide from the original 54 amino acids to 10 amino acids or less, and by substituting key amino acid residues at proteolytically sensitive sites, highly active agonists were produced. These agonist analogues induced brief elevations in gonadotropin and testosterone levels in animals and humans, followed by rapid reductions in these hormones on chronic exposure. These inhibitory effects were more rapid and more complete than those observed with a classical GnRH agonist, leuprolide. This is a remarkable observation in view of kisspeptin actions operating upstream of $\mathrm{GnRH}$ and will require detailed experimentation to reveal the mechanisms involved.

\section{References}

1 Grachev P, Millar RP, O’Byrne KT: The role of neurokinin $\mathrm{B}$ signalling in reproductive neuroendocrinology. Neuroendocrinology 2014;99:7-17.

2 Goodman RL, Coolen LM, Lehman MN: A role for neurokinin B in pulsatile GnRH secretion in the ewe. Neuroendocrinology 2014;99:18-32.

-3 Wakabayashi Y, Yamamura T, Sakamoto K, Mori Y, Okamura H: Electrophysiological and morphological evidence for synchronized GnRH pulse generator activity among kisspeptin/neurokinin B/dynorphin A (KNDy) neurons in goats. J Reprod Dev 2013; 59:40-48.
-4 Hrabovszky E: Neuroanatomy of the human hypothalamic kisspeptin system. Neuroendocrinology 2014;99:33-48.

5 Young J, George JT, Tello JA, Francou B, Bouligand J, Guiochon-Mantel A, Brailly-Tabard S, Anderson RA, Millar RP: Kisspeptin restores pulsatile LH secretion in patients with neurokinin B signaling deficiencies: physiological, pathophysiological and therapeutic implications. Neuroendocrinology 2013;97: 193-202.

6 Matsui H, Asami T: Effects and therapeutic potentials of kisspeptin analogs: regulation of the hypothalamic-pituitary-gonadal axis. Neuroendocrinology 2014;99:49-60. 